\title{
HIV-1 Nef: a multifaceted modulator of T cell receptor signaling
}

\author{
Libin Abraham ${ }^{1,2}$ and Oliver T Fackler ${ }^{1 *}$
}

\begin{abstract}
Nef, an accessory protein of the Human Immunodeficiency Virus type 1 (HIV-1), is dispensable for viral replication in cell culture, but promotes virus replication and pathogenesis in the infected host. Acting as protein-interaction adaptor, HIV-1 Nef modulates numerous target cell activities including cell surface receptor expression, cytoskeletal remodeling, vesicular transport, and signal transduction. In infected T-lymphocytes, altering T-cell antigen receptor (TCR) signaling has long been recognized as one key function of the viral protein. However, reported effects of Nef range from inhibition to activation of this cascade. Recent advances in the field begin to explain these seemingly contradictory observations and suggest that Nef alters intracellular trafficking of TCR proximal machinery to disrupt plasma membrane bound TCR signaling while at the same time, the viral protein induces localized signal transduction at the trans-Golgi network. This review summarizes these new findings on how HIV-1 Nef reprograms TCR signalling output from a broad response to selective activation of the RAS-Erk pathway. We also discuss the implications of these alterations in the context of HIV-1 infection and in light of current concepts of TCR signal transduction.
\end{abstract}

Keywords: HIV/AIDS, Nef, T-cell receptor signaling, Microclusters

\section{Background}

\section{T-cell receptor signaling}

Development, proliferation and immune functions of Tlymphocytes are regulated by their activation state [1]. In concert with co-stimulatory signals, T-cell activation is primarily governed by engagement of surface exposed T-Cell Antigen Receptor (TCR) complexes with Major Histocompatibility Complex (MHC) bound peptides on antigen-presenting cells (APC). These interactions occur physiologically in the context of stable cell-cell contacts referred to as immunological synapse (IS) and trigger a broad range of downstream signaling events including sequential tyrosine phosphorylation cascades, rapid elevation of intracellular calcium flux and dynamic F-actin remodeling [2-11]. These plasma membrane-associated and cytoplasmic events are transmitted to the nucleus by activation and/or import of transcription factors that launch specific transcriptional profiles characteristic for activated T-cells, including induced expression of the T-cell survival cytokine interleukin 2 (IL-2).

\footnotetext{
* Correspondence: oliver.fackler@med.uni-heidelberg.de

${ }^{1}$ Department of Infectious Diseases, Virology, University Hospital Heidelberg INF 324, Heidelberg 69120, Germany

Full list of author information is available at the end of the article
}

TCR signaling in $\mathrm{CD} 4^{+} \mathrm{T}$-cells is initiated by the interaction of the TCR $\alpha, \beta$ subunits with peptide-loaded MHC-II causing spatial rearrangements of the multisubunit TCR complex. As one result of peptide loading, the cytoplasmic TCR zeta chain undergoes conformational changes to expose immunoreceptor tyrosine-based activation motifs (ITAMs), which become subsequently phosphorylated by the Src family kinase Lck (lymphocytespecific protein tyrosine kinase) [12]. Phospho-ITAMs recruit the downstream kinase ZAP-70 (zeta chain associated protein of $70 \mathrm{kDa}$ ), which is also phosphorylated and activated by Lck $[10,13,14]$. Active ZAP-70 now initiates a cascade of phosphorylation events, with the most important ZAP-70 phosphorylation substrates being the trans-membrane adapter protein LAT (linker for the activation of T-cells) and the cytosolic adapter protein SLP76 (Src homology 2 (SH2) domain-containing leukocyte phosphoprotein of $76 \mathrm{kD}$ ) [11,13,15-18]. These two adapters form the backbone of a signaling complex that organizes an array of effector molecules in the correct spatiotemporal manner to allow for the activation of multiple downstream signaling pathways. These include PLC 11 (phospholipase $\mathrm{C} \gamma 1$ ) that controls intracellular $\mathrm{Ca}$

\section{Biomed Central}


${ }^{(2+)}$ flux, F-actin remodeling, cell adhesion and activation of the MAPK pathway, that all together synergize to optimal production of IL-2 by activation of transcription factors such as NFAT (nuclear factor of activated T-cells) and AP-1 (activator protein-1) $[11,13,17,18]$. Thus, signals emanating from Lck trigger TCR proximal signal transduction and are diversified and channeled to multiple downstream signaling pathways by LAT-SLP-76 adaptor scaffolds that act as mirco-signalosomes (Figure 1) $[17,18]$. In this scenario, individual signal transduction steps are spatially separated: TCR engagement triggers the segregation of initial signaling modules including TCR, Lck and ZAP-70 ('primary signaling domains') from LAT-SLP-76 signaling scaffolds that are considered 'secondary signaling domains' or 'signal diversification and regulation modules' $[13,19,20]$. Subsequent TCR distal events are compartmentalized due to the localization of RAS signaling to Golgi membranes [21-28].

\section{Organization of TCR proximal signaling microclusters}

This physical segregation of key TCR proximal signaling molecules can be visualized at the IS by virtue of their

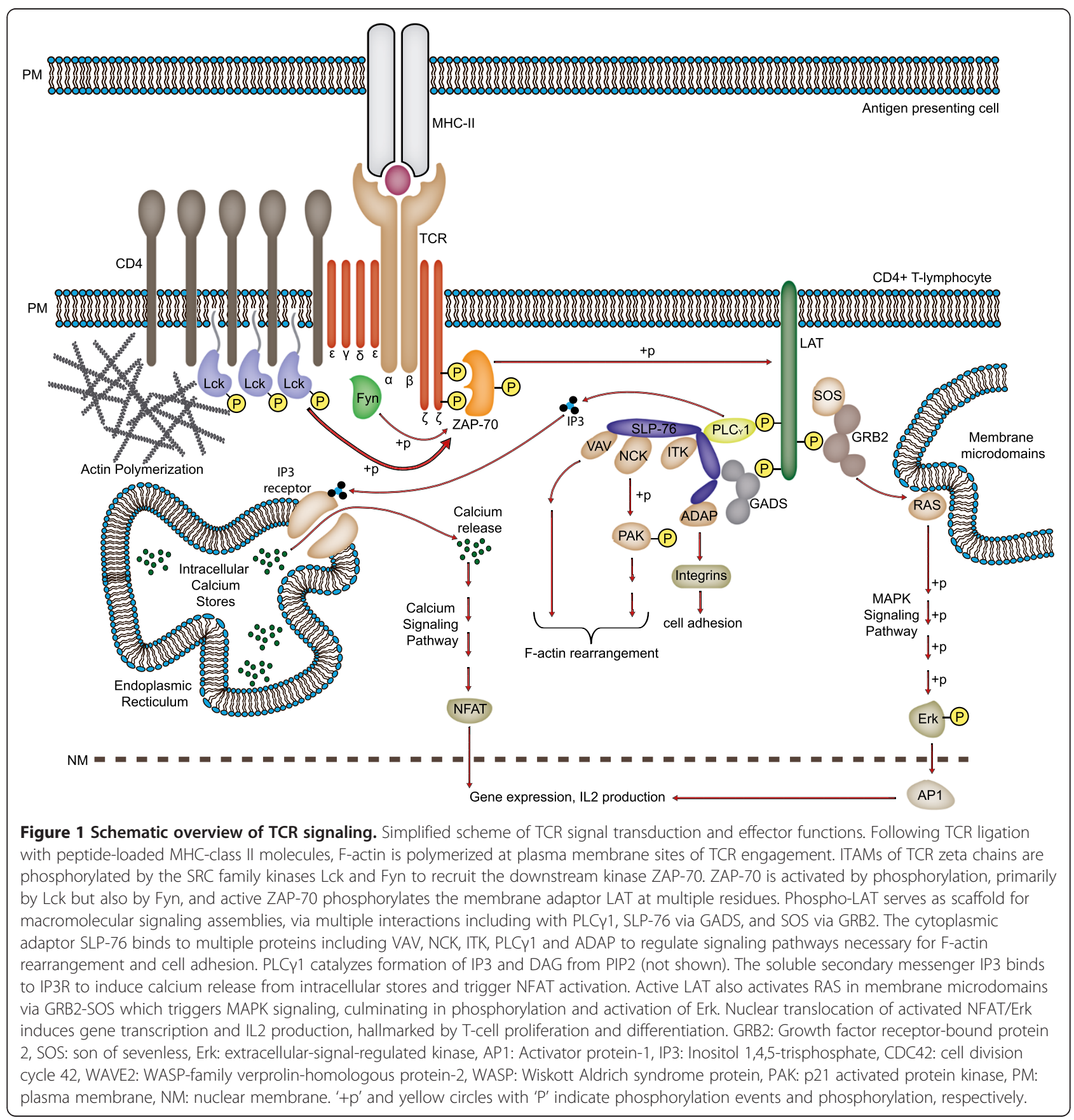


organization in distinct supra molecular activation clusters (SMAC) that, depending on their position relative to the IS, are referred to as central, peripheral and distal SMAC $[2,5,29,30]$. Providing T-lymphocytes with planar surface-bound TCR stimulation in the form of lipid bilayers or coated glass surfaces allows to detect the formation of proximal TCR signal transduction units referred to as microclusters (MCs) [31]. MCs are formed within seconds after initial TCR engagement by clustering of the TCR complex itself and various TCR proximal signaling molecules, range from $30-300 \mathrm{~nm}$ in size [32], and are considered 'signaling hotspots' essential for Tcell activation [29,32-35]. The most widely studied MCs are those nucleated around the TCR itself (TCR MCs) and around the adaptor proteins LAT and SLP-76 (LAT/ SLP-76 MCs). It is well established that activation of Tcell requires the formation of these structures [31,36,37]. Both actin dynamics and microtubule-mediated vesicular transport play important roles in orchestrating the induction and dynamic movement of signaling MCs [5,10,11,30,38-40], subsequently leading to downstream signaling and expression of target genes. Proximal TCR signaling can thus be viewed as a consequence of highly coordinated interactions of individual signaling modules with specific composition and spatio-temporal regulation.

\section{Coupling of HIV-1 replication to T-cell activation}

HIV-1, the causative agent of the Acquired Immunodeficiency Syndrome, AIDS, infects target cells that present the entry receptors and co-receptors CD4 and CXCR4/ CCR5 on their surface. This receptor specificity determines the tropism of HIV-1 for $\mathrm{CD}^{+}{ }^{+}$T-lymphocytes and monocytes/macrophages that constitute the main target cells of the virus in its human host. In particular in $\mathrm{CD}_{4}{ }^{+}$T-lymphocytes, the efficacy of HIV-1 replication is tightly coupled to the activation state of these target cells: while HIV-1 readily undergoes multiple rounds of replication in activated memory $\mathrm{CD} 4^{+} \mathrm{T}$-cells, resting helper $\mathrm{T}$-cells are refractory to productive infection [41-46]. Blocks to HIV-1 infection in resting $\mathrm{CD} 4^{+}$ T-lymphocytes include the entry step, completion of reverse transcription (RT) of incoming viral RNA genomes into DNA, nuclear import and integration of the viral genome, as well as transcription of viral genes [45-49]. The barrier to viral entry is posed by the rigid cortical actin layer and HIV-1 triggers specific signaling cascades to bypass this obstacle, explaining why HIV-1 entry is readily observed in resting $\mathrm{CD}^{+} \mathrm{T}$-lymphocytes [50]. The block to reverse transcription is controlled by the recently identified host cell restriction factor Samhd1 [51-53]. This Samhd1 dependent restriction might reflect the ability of this enzyme to reduce the pool of available dNTPs required for RT in resting but not activated T-lymphocytes, the latter of which display significantly higher dNTP levels. Inefficient transcription of viral genes in resting $\mathrm{T}$-cells finally mirrors the low abundance/activity of host cell transcription factors such as nuclear factor- $\mathrm{kB}(\mathrm{NF}-\mathrm{kB})$ and NFAT required for initial rounds of viral transcription prior to synthesis of the viral transcription factor Tat [49,54-57]. Together, this implies that the activation state of target $\mathrm{CD}_{4}^{+} \mathrm{T}$ lymphocytes not only dictates the success rate of HIV-1 infection of previously uninfected target cells, but also determines how efficiently integrated proviral genes are transcribed, and thus new virus particles are synthesized in latently infected resting cells upon encounter with Tcell stimuli. Of note, activation of full rounds of HIV-1 replication in resting $\mathrm{T}$-cells can be achieved by inducing yet ill-defined, intermediate levels of T-cell activation [58]. This preference of HIV-1 for target T-lymphocytes with intermediate activation states may reflect that potent activation through TCR ligation can trigger activation induced cell death (AICD) [59,60] which would significantly reduce the life span of productively infected $\mathrm{CD}^{+}{ }^{+} \mathrm{T}$-cells and may thus self-limit spread of HIV-1 infection. It is thus plausible that HIV-1 applies strategies to fine tune T-cell activation in infected cells in order to optimize its replication. The viral protein Nef emerges as a central viral player in this scenario and this review will summarize recent advances in our understanding on the mechanisms employed by Nef.

\section{The Nef protein and its effects on TCR signaling}

Nef is a small $27-35 \mathrm{kDa}$ myristoylated protein encoded the primate lentiviruses (HIV-1, HIV-2 and SIV) that localizes to the cytoplasm of infected cells and is partially recruited to cellular membranes. Nef is dispensable for HIV-1 replication in cell culture, however in the infected host, the viral protein markedly elevates virus titers and is required for rapid disease progression [61-63]. Nef is therefore considered a key factor in AIDS pathogenesis $[44,64]$. It is generally assumed that $\mathrm{Nef}$ exerts this role in AIDS pathogenesis via several independent activities that (i) directly promote HIV-1 replication and (ii) facilitate evasion of infected cells from recognition by the host immune system (see $[64,65]$ for reviews). These activities are mediated by a plethora of suggested interactions with host cell proteins, by which Nef manipulates various aspects of host cell vesicular transport, cytoskeleton dynamics and cell motility, as well as signal transduction $[44,64,66,67]$. In the context of $\mathrm{CD}_{4}^{+} \mathrm{T}$ lymphocytes, most studies since the early days of Nef characterization focused on effects of Nef on T-cell receptor signaling.

The most impressive evidence supporting a direct impact of Nef on T-lymphocyte activation was obtained in 
macaques infected with the acutely lethal SIV variant pbj14, in which T-lymphocyte hyperactivation and subsequent depletion was observed [68]. This effect reflected the ability of this particular Nef variant to trigger T-cell receptor signaling and IL-2 production by virtue of an ITAM motif not present in any other Nef protein [68-70]. Even though significantly milder than Nef from SIVpbj14, HIV-1 Nef was also demonstrated to bear the capacity to enhance basal levels of T-cell activation, especially when physically tethered to the plasma membrane (PM) [71]. These initial observation initiated numerous studies to address extend, mechanism and functional consequence of alterations of TCR signaling by HIV-1 Nef. Presumably due to the use of varying experimental strategies that often involved the use of immortalized cell lines rather than primary cells and marked overexpression of individual proteins, these efforts yielded sometimes contradicting results but generally concluded that HIV-1 Nef inhibits T-cell activation [72-75]. More recent work, including studies based on viral infection of primary target $\mathrm{T}$-cells, revealed that HIV-1 Nef moderately enhances distal responses to exogenous TCR stimulation by mitogens or anti-TCR Abs including enhanced induction of NFAT, NFkB, AP-1 transcriptional activity, the release of calcium, and IL-2 production [50,76-88]. Taken together these studies provided evidence that HIV-1 Nef can lower the threshold for activation of $\mathrm{CD} 4^{+} \mathrm{T}$-lymphocytes, but is not sufficient to cause activation in the absence of exogenous stimuli.

Many aspects of HIV-1 Nef induced TCR signaling dysfunction are also observed with Nef proteins from simian immunodeficiency viruses (SIV) [89-92] which, in contrast to HIV-1, are largely non-pathogenic in their natural host. In addition to the effects exerted by HIV-1 Nef, SIV Nef proteins also efficiently downregulate CD3TCR complexes from the surface of infected T lymphocytes and thus more potently inhibit TCR signaling [83,92-95]. This differential regulation of TCR signaling by HIV-1 and SIV Nef proteins has been suggested as one determinant of the pathogenic outcome of HIV-1 infection in humans $[83,92]$. Since molecular and functional differences between SIV and HIV-1 Nef proteins in this context were already discussed extensively (see reviews $[44,64,96,97])$, this review focuses on recent developments that enhance our understanding of how HIV-1 Nef modulates TCR signaling in infected $\mathrm{CD} 4^{+}$ T-lymphocytes.

The concept that HIV-1 Nef slightly enhances TCR signaling was at odds with another series of studies demonstrating rather pronounced inhibitory effects of $\mathrm{Nef}$ on formation and organization of the IS and thus early events following TCR engagement. One prominent consequence of HIV-1 infection or isolated expression of Nef is pronounced accumulation of the TCR itself and the proximal kinase Lck in an intracellular compartment $[89,90,98,99]$. Based on these findings, Nef interferes with essential hallmarks of TCR signal initiation, leaving the field with the paradoxal situation that Nef facilitates some aspects of distal TCR signaling while early events in the TCR cascade are potently inhibited by the viral protein. Recent studies now started to provide more detailed insight into the mechanisms underlying these seemingly contradictory effects of Nef, allowing depiction of an integrative view on how Nef rewires TCR signaling by affecting both, TCR proximal and distal events.

\section{Decompartmentalization of TCR signaling by HIV-1 Nef}

The finding that Nef retargets Lck, the master switch kinase of early TCR signaling, away from the plasma membrane to early and recycling endosomes (RE) as well as the trans-Golgi network (TGN) provided a first important clue $[98,100]$. Since TCR signaling is initiated and sustained at the PM and Lck is essential to this process, this finding was entirely consistent with the disruption of early TCR signaling observed in Nef expressing $\mathrm{CD}_{4}^{+}$T-lymphocytes. However, only with the recent determination of the subcellular localization of kinase-active Lck, it became evident that this retargeting might also be linked to the ability of Nef to enhance distal aspects of TCR signaling [100]. The use of phosphospecific antibodies revealed that RE/TGN associated Lck subpopulations in Nef expressing cells are in the catalytically active conformation and thus signaling competent. Of note, this intracellular enrichment of active Lck kinase was observed already in the absence of exogenous TCR stimulation, indicating that Nef may generate constitutive intracellular signals. While the majority of early TCR signaling occurs at the plasma membrane, compartmentalization of the pathway has been described in the activation of the RAS GTPase, which takes place at intracellular membranes, including the Golgi apparatus [21-28]. Similar to activation of the phosphotyrosine cascade at the PM, also RAS activation depends on prior induction of Lck [27]. Consistently, the enrichment of active Lck at RE/TGN compartments induced by Nef resulted in an increase of localized RAS activity and enhanced activation of Erk kinase as well as IL-2 production downstream of RAS in response to exogenous stimulation [100] (see Figure 2). This effect may synergize to potentiate transcriptional activation of downstream target genes with the ability of Nef to (i) promote, via interactions with the IP3 receptor, the release of calcium from intracellular stores [81] and (ii) trigger Erk activity via association with the Nefassociated kinase complex NAKC [101-103].

Together, these findings provide an explanation for the observed Nef-mediated disruption of early TCR signaling and selective, stimulus-independent sensitization of 


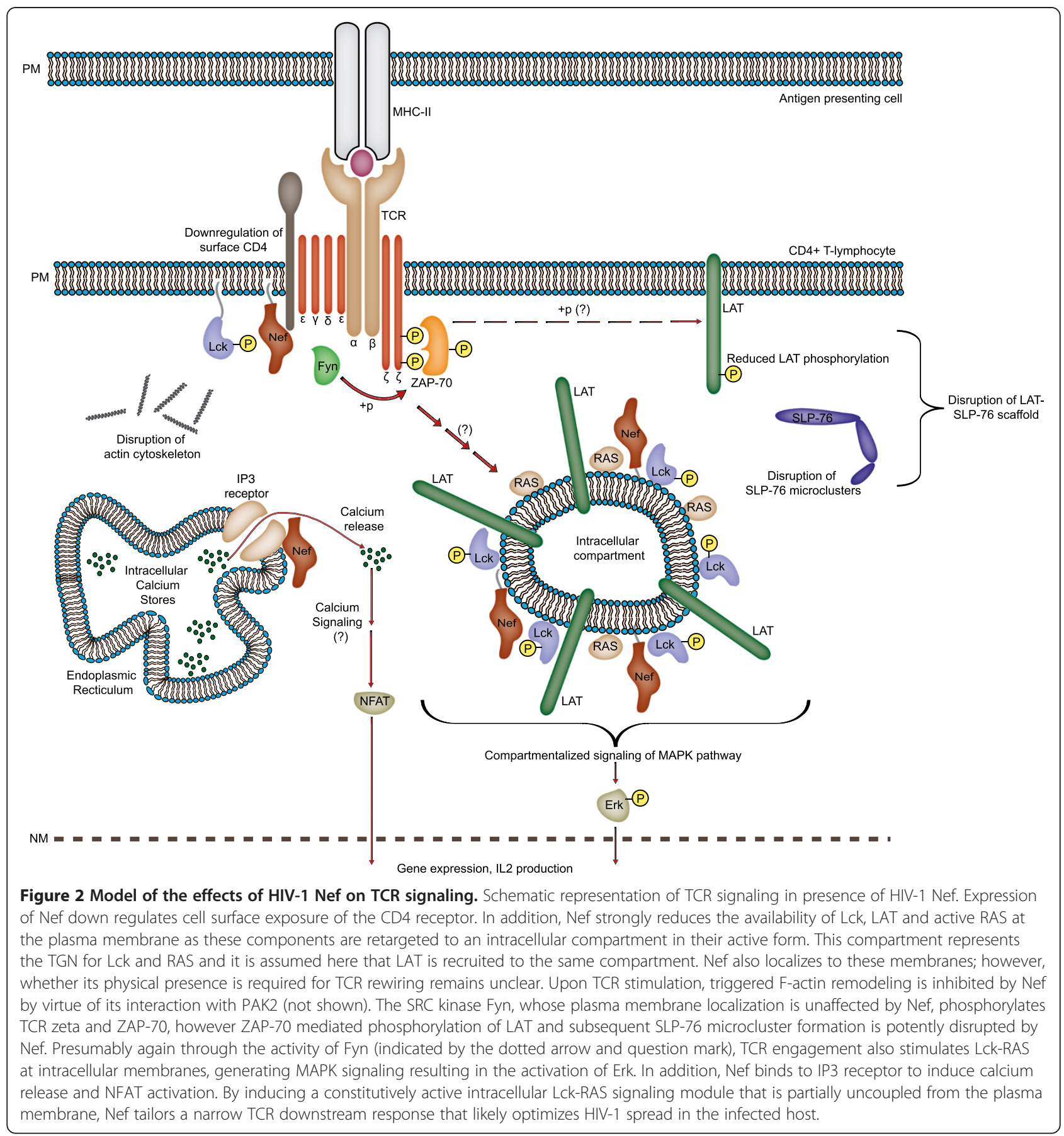

the RAS pathway: by aggregating a specific set of signaling competent TCR effectors away from the PM to the TGN, Nef tailors TCR responses from a typically broad cascade of effectors to a specific activation of the RAS pathway. However, the effect of Nef on signaling downstream of RAS becomes only apparent following TCR engagement, raising the question how such signal transmission might occur in the absence of Lck from the PM. It has long been noted that the pivotal role of Lck in proximal TCR signaling can be substituted by the closely related Src kinase Fyn, however, breadth and magnitude of this functional redundancy has remained controversial [12,104-108]. Interestingly and in sharp contrast to Lck, the localization of active Fyn was unaltered in Nef expressing cells prior and following TCR stimulation [100]. Selective interference of Nef with PM localization of Lck but not of Fyn may account for the residual responsiveness of Nef-expressing or HIV-1 infected cells to TCR stimulation. 


\section{Disruption of proximal TCR events}

Recent studies also provided surprising insights into the complexity of mechanisms employed by HIV-1 Nef to disrupt early TCR signaling events. Earlier work had already established that Nef interferes with actin remodeling and cell spreading triggered by TCR engagement $[89,90,99]$. On the molecular level, Nef controls actin dynamics by virtue of its association with the cellular kinase PAK2, which is turned by Nef to phosphorylate and thus inactivate the actin severing factor cofilin to reduce actin remodeling [91,109]. It however became increasingly clear that this actin-mediated mechanism may be necessary but not sufficient for the observed disruption of early TCR signaling. Taking advantage of the TCR microcluster concept for visualization and quantification of effects of Nef on early TCR signaling allowed the identification of the specific steps affected by Nef. Again possibly reflecting the action of Fyn and in line with earlier reports [89,92], Nef had no effect on the extend of ZAP-70 activation or its organization in signaling microclusters [110]. ZAP-70 activation therefore does not require cell spreading and dynamic actin remodeling. Pronounced defects, however, were observed in the presence of Nef for the organization of the adaptor protein SLP-76 in microcluster. As a consequence, physical association between SLP-76 and LAT, a key event in TCR signal transmission, was drastically reduced by the viral protein. Interestingly, further mechanistic analysis revealed this effect to be mediated by Nef via simultaneous interference with actin remodeling/cell spreading and disruption of the subcellular localization of LAT. Very similar to the effect on Lck, Nef induced the accumulation of LAT in intracellular compartments [110]. Nef mediated retargeting of both proteins can be overcome by coexpression of the anterograde transport adaptor Unc119 [100,110]. How Unc119, which is physiologically involved in the anterograde transport of Lck by virtue of its interaction with the GTPase Rab11 [111], acts to overwrite the Nef-mediated block and whether this reflects the involvement of endogenous Unc119 in the inhibitory action of Nef remains to be determined.

\section{Functional consequences of Nef-mediated alterations of TCR signaling}

The fact that evolution selected for several mechanisms by which HIV-1 Nef synergistically tunes TCR signaling suggests that this provides HIV with a decisive advantage in the infected host. It is well established that effects of Nef on HIV-1 replication in T-lymphocyte cultures are most pronounced when unstimulated cells are infected and only subsequently subjected to TCR stimulation [112,113]. This positive effect on HIV-1 replication appears to correlate with the ability of Nef to induce RE/TGN-associated signaling [100]. This may reflect e.g. that activation induced cell death of Nefexpressing cells following TCR stimulation is slightly reduced relative to non-Nef expressing control cells and that Nef-tailored TCR signaling could promote HIV-1 transcription $[83,114]$. However, the Nef effect on virus replication in this cell system is modest and in magnitude significantly lower than that observed in e.g. SIV infected rhesus macaques [63]. Its relevance in the context of an immunocompetent host is hence unclear. It appears thus plausible that Nef-tailored TCR responses bear consequences that affect HIV-1 spread and pathogenesis beyond its direct replicative capacity. Nef has been reported to trigger the release of exosome microvesicles that are massively secreted to bystander cells upon T-cell activation [115,116]. Enhanced exosome release was directly linked to activation of Erk signaling via the association of Nef with a large cellular kinase complex referred to as NAKC [101,103,117]. Mechanisms of decompartmentalization of TCR signaling and Erk activation may thus integrate to modulate exosome release in response to TCR activation, with the Erk-RAS pathway emerging as the central target of Nef action. Depending on their composition and cargo, such exosomes could possibly render non-infected bystander cells more susceptible for infection or undermine potent immune recognition of already infected cells. On the other hand, Nef has been implicated as a major determinant of killing of non-infected $\mathrm{CD} 4^{+}$T-lymphocytes in HIV-1 infection of tonsil histocultures [118-120] and, much more prominently, in humanized mice [121]. Since Nefinduced exosomes are able to induce such bystander Tcell killing [116], triggering exosome release from HIV-1 infected cells may represent a major pathogenic determinant of this viral protein. With the enhanced understanding of the molecular mechanisms by which Nef alters T-lymphocyte responses to TCR stimulation, future investigations will undoubtedly focus on defining the patho-physiological role of these mechanisms.

\section{HIV-1 Nef in context of the sub-synaptic LAT concept}

Studying the effects of HIV-1 Nef on TCR signaling not only provides insight into the patho-physiological mechanism of the viral protein but also contributes to our understanding of the general principles of TCR signal transduction. According to an emerging concept of TCR signaling, most of the LAT clusters at the plasma membrane are inactive at steady state and do not contribute significantly to signaling upon T-cell activation. Rather, sub-synaptic vesicles containing LAT are recruited to the plasma membrane upon TCR engagement to facilitate microcluster-dependent signaling $[30,122,123]$. These 
LAT positive vesicles move rapidly in a random manner, making transient visits at both TCR-ZAP-70 and SLP-76 clusters. Notably, colocalization of LAT containing vesicles with TCR-ZAP-70 microclusters correlates with phosphorylation of LAT [122] suggesting that LAT positive vesicles interact closely with the PM and are phosphorylated by kinases associated with triggered TCRs $[30,123]$. This model provides an attractive concept for the spatio-temporal regulation of LAT's interactions with the TCR machinery [30] but has remained controversial. The recent mechanistic studies on how HIV-1 Nef usurps TCR signaling are in line with an important role of sub-synaptic LAT in TCR signaling $[100,110]$. Notably, Nef-expressing cells fail to generate functional p-LAT microclusters despite the presence of LAT containing microcluster at the IS. Conceivably, the pronounced intracellular accumulation of LAT induced by the viral protein prevents recruitment of LAT to the PM and thus functionalization of LAT microclusters post TCR stimulation [110]. This intracellularly accumulated LAT population in Nef expressing cells likely represents a sub-synaptic LAT vesicle pool that is prevented from translocating to TCR activation sites. In this scenario, interference with translocation of sub-synaptic LAT would be one mechanism by which Nef disrupts TCR signaling downstream of LAT. However, this disruption does not only depend on Nef's ability to target LAT containing vesicles to this yet to be defined intracellular compartment, but also requires Nef to interfere with TCR-induced actin dynamics. This predicts that also in physiological T-cell signaling, dynamic actin remodeling may be critical for translocation of LAT positive vesicles to TCR activation sites, allowing phosphorylation of the adaptor protein and subsequent downstream signaling events.

\section{The LAT-SLP-76 module as target for pathogens other than HIV-1}

Emphasizing the central role of TCR signaling for pathogen-host interactions, targeted modulation of LATSLP-76 adaptors is also employed by other proteins encoded by viral and non-viral pathogens. One example is the 12 protein of human T-cell leukemia/lymphoma virus type 1 (HTLV-1) that inhibits the phosphorylation of LAT post TCR stimulation [124]. It is believed that by decreasing T-cell responsiveness to TCR stimulation, p12 selectively curtails viral expression to minimize immune recognition of infected $\mathrm{CD} 4^{+} \mathrm{T}$-cells and impair the function of infected cytotoxic $\mathrm{CD}^{+} \mathrm{T}$-cells, thereby providing a favorable environment for viral persistence in the infected host. Similar strategies were also identified for the gram-negative bacterium Yersinia, whose virulence factor $\mathrm{YopH}$ specifically limits phosphorylation of LAT and SLP-76 to inhibit T-cell activation and thus alter T-cell mediated immune responses [125]. Finally, the T-lymphotropic tumor virus herpesvirus saimiri encodes for a "viral version" of LAT that triggers T-cell activation in infected cells by partially substituting for functions of cellular LAT [126]. Taken together, modulation of LAT-SLP-76 adaptors thus emerges as a strategy frequently used by various pathogens to adapt T-cell responses to their specific needs.

\section{Model of Nef action in TCR signaling}

Together a scenario emerges in which Nef tailors TCR responses by relocalizing TCR proximal signaling from the PM to the RE/TGN (Figure 2). This is achieved by modulating vesicular transport routes that govern the transport of essential TCR proximal machinery such as Lck and LAT to the PM and by disrupting TCR-induced actin remodeling events critical for the spatio-temporal coordination of TCR proximal signaling machinery. Besides reducing the concentration of these components at plasma membrane sites of TCR engagement, these alterations also result in an enrichment of signaling competent TCR machinery at the RE/TGN. Still responsive to TCR engagement at the PM via the activity of Fyn, this intracellular pool triggers selective downstream pathways including activation of Erk. Presumably, many other TCR downstream effectors will not be induced in this configuration, suggesting that Nef tailors the response to TCR stimulation from a broad cascade to a specific and targeted activation of the RAS-Erk pathway. Consistent with the large body of existing literature, Nef thus can both activate and inhibit select aspects of TCR signaling and which effect predominates is likely dictated by the precise activation state of the T-lymphocyte used [88].

\section{Concluding remarks}

Which effects HIV-1 Nef exerts on TCR signaling has remained a controversial issue with many reports describing either activating or inhibitory effects of the viral protein on select aspects of TCR signaling. Emerging evidence allows integrating these seemingly contradictory findings into a unifying model. In this scenario, Nef disrupts important TCR proximal events and simultaneously sensitizes specific downstream aspects of compartmentalized TCR signaling. This strategy allows Nef to optimize HIV-1 replication in $\mathrm{CD}^{+}$T-lymphocytes, but may also facilitate additional processes such as cellcell communication that exert indirect effects on virus spread and/or pathogenesis. The fact that important human pathogens such as HIV-1 or HTLV-I target TCR signaling underscores the central role of this pathway for host cell interactions of T-cell tropic pathogens. The responsible pathogen factors represent valuable tools for dissecting the molecular basis of TCR signaling. 


\section{Abbreviations}

dNTP: Deoxyribonucleotide triphosphate; HIV: Human Immunodeficiency virus; IS: Immunological synapse; ITAM: Immunoreceptor tyrosine-based activation motif; LAT: Linker of Activated T-cells; Lck: Lymphocyte-specific protein tyrosine kinase; MAPK: Mitogen activated protein kinase; MCs: Microclusters; MHC: Major Histocompatibility Complex; NAKC: Nefassociated kinase complex; PM: Plasma membrane; RE: Recycling endosome; RT: Reverse transcription; SIV: Simian immunodeficiency virus; SLP-76: Src homology $2(\mathrm{SH} 2)$ domain-containing leukocyte phosphoprotein of $76 \mathrm{kD}$; TCR: T-cell antigen receptor; TGN: Trans-Golgi network; ZAP-70: Zeta-chainassociated protein kinase 70

\section{Competing interests}

The authors declare that they have no competing interests.

\section{Authors' contributions}

LA generated the figures and OTF wrote manuscript together with LA. Both authors read and approved the final manuscript.

\section{Acknowledgements}

Our research is supported by the Deutsche Forschungsgemeinschaft (project 15 within TRR83 to OTF; cluster of excellence EXO81: PhD fellowship to LA).

\section{Author details}

'Department of Infectious Diseases, Virology, University Hospital Heidelberg, INF 324, Heidelberg 69120, Germany. ${ }^{2}$ The Hartmut Hoffmann-Berling International Graduate School of Molecular and Cellular Biology, INF 501, Heidelberg 69120, Germany.

Received: 23 October 2012 Accepted: 28 November 2012 Published: 10 December 2012

\section{References}

1. Smith-Garvin JE, Koretzky GA, Jordan MS: T cell activation. Annu Rev Immunol 2009, 27:591-619.

2. Monks CR, Freiberg BA, Kupfer H, Sciaky N, Kupfer A: Three-dimensional segregation of supramolecular activation clusters in T cells. Nature 1998, 395:82-86.

3. Grakoui A, Bromley SK, Sumen C, Davis MM, Shaw AS, Allen PM, Dustin ML. The immunological synapse: a molecular machine controlling $T$ cell activation. Science 1999, 285:221-227.

4. Krummel MF, Cahalan MD: The immunological synapse: a dynamic platform for local signaling. J Clin Immunol 2010, 30:364-372.

5. Dustin ML, Chakraborty AK, Shaw AS: Understanding the structure and function of the immunological synapse. Cold Spring Harb Perspect Biol 2010, 2:a002311.

6. Schlessinger J: Cell signaling by receptor tyrosine kinases. Cell 2000, 103:211-225.

7. Samelson LE: Signal transduction mediated by the $T$ cell antigen receptor: the role of adapter proteins. Annu Rev Immunol 2002, 20:371-394.

8. Luik RM, Lewis RS: New insights into the molecular mechanisms of store-operated Ca2+ signaling in T cells. Trends Mol Med 2007, 13:103-107.

9. Huse M, Klein LO, Girvin AT, Faraj JM, Li QJ, Kuhns MS, Davis MM: Spatial and temporal dynamics of T cell receptor signaling with a photoactivatable agonist. Immunity 2007, 27:76-88.

10. Acuto O, Cantrell D: T cell activation and the cytoskeleton. Annu Rev Immunol 2000, 18:165-184

11. Billadeau DD, Nolz JC, Gomez TS: Regulation of T-cell activation by the cytoskeleton. Nat Rev Immunol 2007, 7:131-143.

12. van Oers NS, Killeen N, Weiss A: Lck regulates the tyrosine phosphorylation of the T cell receptor subunits and ZAP-70 in murine thymocytes. J Exp Med 1996, 183:1053-1062.

13. Acuto O, Di Bartolo V, Michel F: Tailoring T-cell receptor signals by proximal negative feedback mechanisms. Nat Rev Immunol 2008, 8:699-712.

14. van Oers NS, Tohlen B, Malissen B, Moomaw CR, Afendis S, Slaughter CA: The 21- and 23-kD forms of TCR zeta are generated by specific ITAM phosphorylations. Nat Immunol 2000, 1:322-328.
15. Bubeck Wardenburg J, Fu C, Jackman JK, Flotow H, Wilkinson SE, Williams DH, Johnson R, Kong G, Chan AC, Findell PR: Phosphorylation of SLP-76 by the ZAP-70 protein-tyrosine kinase is required for T-cell receptor function. J Biol Chem 1996, 271:19641-19644.

16. Zhang W, Sloan-Lancaster J, Kitchen J, Trible RP, Samelson LE: LAT: the ZAP-70 tyrosine kinase substrate that links $\mathrm{T}$ cell receptor to cellular activation. Cell 1998, 92:83-92.

17. Balagopalan L, Coussens NP, Sherman E, Samelson LE, Sommers CL: The LAT story: a tale of cooperativity, coordination, and choreography. Cold Spring Harb Perspect Biol 2010, 2:a005512.

18. Koretzky GA, Abtahian F, Silverman MA: SLP76 and SLP65: complex regulation of signalling in lymphocytes and beyond. Nat Rev Immunol 2006, 6:67-78.

19. Wilson BS, Pfeiffer JR, Surviladze Z, Gaudet EA, Oliver JM: High resolution mapping of mast cell membranes reveals primary and secondary domains of Fc(epsilon)RI and LAT. J Cell Biol 2001, 154:645-658.

20. Lillemeier BF, Pfeiffer JR, Surviladze Z, Wilson BS, Davis MM: Plasma membrane-associated proteins are clustered into islands attached to the cytoskeleton. Proc Natl Acad Sci USA 2006, 103:18992-18997.

21. Ibiza S, Perez-Rodriguez A, Ortega A, Martinez-Ruiz A, Barreiro O, Garcia-Dominguez CA, Victor VM, Esplugues JV, Rojas JM, Sanchez-Madrid F, Serrador JM: Endothelial nitric oxide synthase regulates N-Ras activation on the Golgi complex of antigen-stimulated T cells. Proc Natl Acad Sci USA 2008, 105:10507-10512.

22. Mor A, Campi G, Du G, Zheng Y, Foster DA, Dustin ML, Philips MR: The lymphocyte function-associated antigen-1 receptor costimulates plasma membrane Ras via phospholipase D2. Nat Cell Biol 2007, 9:713-719.

23. Perez De Castro I, Bivona TG, Philips MR, Pellicer A: Ras activation in Jurkat $T$ cells following low-grade stimulation of the T-cell receptor is specific to N-Ras and occurs only on the Golgi apparatus. Mol Cell Biol 2004, 24:3485-3496

24. Choy E, Chiu VK, Silletti J, Feoktistov M, Morimoto T, Michaelson D, Ivanov IE, Philips MR: Endomembrane trafficking of ras: the CAAX motif targets proteins to the ER and Golgi. Cell 1999, 98:69-80.

25. Apolloni A, Prior IA, Lindsay M, Parton RG, Hancock JF: H-ras but not K-ras traffics to the plasma membrane through the exocytic pathway. Mol Cell Biol 2000, 20:2475-2487.

26. Walker SA, Lockyer PJ: Visualizing Ras signalling in real-time. J Cell Sci 2004, 117:2879-2886.

27. Mor A, Philips MR: Compartmentalized Ras/MAPK signaling. Annu Rev Immunol 2006, 24:771-800.

28. Fehrenbacher N, Bar-Sagi D, Philips M: Ras/MAPK signaling from endomembranes. Mol Oncol 2009, 3:297-307.

29. Varma R, Campi G, Yokosuka T, Saito T, Dustin ML: T cell receptor-proximal signals are sustained in peripheral microclusters and terminated in the central supramolecular activation cluster. Immunity 2006, 25:117-127.

30. Dustin ML, Depoil D: New insights into the T cell synapse from single molecule techniques. Nat Rev Immunol 2011, 11:672-684.

31. Bunnell SC, Hong DI, Kardon JR, Yamazaki T, McGlade CJ, Barr VA, Samelson LE: T cell receptor ligation induces the formation of dynamically regulated signaling assemblies. J Cell Biol 2002, 158:1263-1275.

32. Yokosuka T, Saito T: The immunological synapse, TCR microclusters, and T cell activation. Curr Top Microbiol Immunol 2010, 340:81-107.

33. Campi G, Varma R, Dustin ML: Actin and agonist MHC-peptide complex-dependent T cell receptor microclusters as scaffolds for signaling. J Exp Med 2005, 202:1031-1036.

34. Yokosuka T, Sakata-Sogawa K, Kobayashi W, Hiroshima M, Hashimoto-Tane A, Tokunaga M, Dustin ML, Saito T: Newly generated T cell receptor microclusters initiate and sustain $\mathrm{T}$ cell activation by recruitment of Zap70 and SLP-76. Nat Immunol 2005, 6:1253-1262.

35. Yokosuka T, Saito T: Dynamic regulation of T-cell costimulation through TCR-CD28 microclusters. Immunol Rev 2009, 229:27-40.

36. Bunnell SC, Singer AL, Hong DI, Jacque BH, Jordan MS, Seminario MC, Barr VA, Koretzky GA, Samelson LE: Persistence of cooperatively stabilized signaling clusters drives T-cell activation. Mol Cell Biol 2006, 26:7155-7166.

37. Bunnell SC: Multiple microclusters: diverse compartments within the immune synapse. Curr Top Microbiol Immunol 2010, 340:123-154.

38. Huse M: Microtubule-organizing center polarity and the immunological synapse: protein kinase $\mathrm{C}$ and beyond. Front Immunol 2012, 3:235. 
39. Martin-Cofreces NB, Baixauli F, Lopez MJ, Gil D, Monjas A, Alarcon B, Sanchez-Madrid F: End-binding protein 1 controls signal propagation from the T cell receptor. EMBO J 2012, 31:4140-4152.

40. Lasserre R, Alcover A: Microtubule dynamics and signal transduction at the immunological synapse: new partners and new connections. EMBO J 2012, 31:4100-4102

41. Bukrinsky MI, Stanwick TL, Dempsey MP, Stevenson M: Quiescent T lymphocytes as an inducible virus reservoir in HIV-1 infection. Science 1991, 254:423-427.

42. McDougal JS, Mawle A, Cort SP, Nicholson JK, Cross GD, Scheppler-Campbell JA, Hicks D, Sligh J: Cellular tropism of the human retrovirus HTLV-III/LAV. I. Role of T cell activation and expression of the T4 antigen. J Immunol 1985, 135:3151-3162.

43. Stevenson M: HIV-1 pathogenesis. Nat Med 2003, 9:853-860.

44. Fackler OT, Alcover A, Schwartz O: Modulation of the immunological synapse: a key to HIV-1 pathogenesis? Nat Rev Immunol 2007, 7:310-317.

45. Zack JA, Arrigo SJ, Weitsman SR, Go AS, Haislip A, Chen IS: HIV-1 entry into quiescent primary lymphocytes: molecular analysis reveals a labile, latent viral structure. Cell 1990, 61:213-222.

46. Stevenson M, Stanwick TL, Dempsey MP, Lamonica CA: HIV-1 replication is controlled at the level of $\mathrm{T}$ cell activation and proviral integration. EMBO J 1990, 9:1551-1560.

47. Wong JK, Hezareh M, Gunthard HF, Havlir DV, Ignacio CC, Spina CA, Richman DD: Recovery of replication-competent HIV despite prolonged suppression of plasma viremia. Science 1997, 278:1291-1295

48. Zack JA, Haislip AM, Krogstad P, Chen IS: Incompletely reverse-transcribed human immunodeficiency virus type 1 genomes in quiescent cells can function as intermediates in the retroviral life cycle. J Virol 1992, $66: 1717-1725$

49. Chiu YL, Soros VB, Kreisberg JF, Stopak K, Yonemoto W, Greene WC: Cellular APOBEC3G restricts HIV-1 infection in resting CD4+ T cells. Nature 2005, 435:108-114.

50. Wu Y, Marsh JW: Selective transcription and modulation of resting T cell activity by preintegrated HIV DNA. Science 2001, 293:1503-1506.

51. Laguette N, Sobhian B, Casartelli N, Ringeard M, Chable-Bessia C, Segeral E, Yatim A, Emiliani S, Schwartz O, Benkirane M: SAMHD1 is the dendriticand myeloid-cell-specific HIV-1 restriction factor counteracted by Vpx. Nature 2011, 474:654-657.

52. Hrecka K, Hao C, Gierszewska M, Swanson SK, Kesik-Brodacka M, Srivastava S, Florens L, Washburn MP, Skowronski J: Vpx relieves inhibition of HIV-1 infection of macrophages mediated by the SAMHD1 protein. Nature 2011, 474:658-661

53. Baldauf HM, Pan X, Erikson E, Schmidt S, Daddacha W, Burggraf M, Schenkova K, Ambiel I, Wabnitz G, Gramberg T, et al: SAMHD1 restricts HIV-1 infection in resting CD4(+) T cells. Nat Med 2012, 18:1682-1689.

54. Lassen KG, Ramyar KX, Bailey JR, Zhou Y, Siliciano RF: Nuclear retention of multiply spliced HIV-1 RNA in resting CD4+ T cells. PLoS Pathog 2006, 2:e68.

55. Kreisberg JF, Yonemoto W, Greene WC: Endogenous factors enhance HIV infection of tissue naive CD4 T cells by stimulating high molecular mass APOBEC3G complex formation. J Exp Med 2006, 203:865-870.

56. Kinoshita S, Chen BK, Kaneshima H, Nolan GP: Host control of HIV-1 parasitism in T cells by the nuclear factor of activated T cells. Cell 1998, 95:595-604.

57. Ganesh L, Burstein E, Guha-Niyogi A, Louder MK, Mascola JR, Klomp LW, Wijmenga C, Duckett CS, Nabel GJ: The gene product Murr1 restricts HIV-1 replication in resting CD4+ lymphocytes. Nature 2003, 426:853-857.

58. Eckstein DA, Penn ML, Korin YD, Scripture-Adams DD, Zack JA, Kreisberg JF, Roederer M, Sherman MP, Chin PS, Goldsmith MA: HIV-1 actively replicates in naive CD4(+) T cells residing within human lymphoid tissues. Immunity 2001, 15:671-682.

59. Arnold R, Brenner D, Becker M, Frey CR, Krammer PH: How T lymphocytes switch between life and death. Eur J Immunol 2006, 36:1654-1658.

60. Bourgeois C, Stockinger B: T cell homeostasis in steady state and lymphopenic conditions. Immunol Lett 2006, 107:89-92.

61. Kirchhoff F, Greenough TC, Brettler DB, Sullivan JL, Desrosiers RC: Brief report: absence of intact nef sequences in a long-term survivor with nonprogressive HIV-1 infection. N Engl J Med 1995, 332:228-232.

62. Deacon NJ, Tsykin A, Solomon A, Smith K, Ludford-Menting M, Hooker DJ, McPhee DA, Greenway AL, Ellett A, Chatfield C, et al: Genomic structure of an attenuated quasi species of HIV-1 from a blood transfusion donor and recipients. Science 1995, 270:988-991.

63. Kestler HW 3rd, Ringler DJ, Mori K, Panicali DL, Sehgal PK, Daniel MD, Desrosiers RC: Importance of the nef gene for maintenance of high virus loads and for development of AIDS. Cell 1991, 65:651-662.

64. Laguette N, Bregnard C, Benichou S, Basmaciogullari S: Human immunodeficiency virus (HIV) type-1, HIV-2 and simian immunodeficiency virus Nef proteins. Mol Aspects Med 2010, 31:418-433.

65. Geyer M, Fackler OT, Peterlin BM: Structure-function relationships in HIV-1 Nef. EMBO Rep 2001, 2:580-585.

66. Roeth JF, Collins KL: Human immunodeficiency virus type 1 Nef: adapting to intracellular trafficking pathways. Microbiol Mol Biol Rev 2006, 70:548-563.

67. Stolp B, Fackler OT: How HIV takes advantage of the cytoskeleton in entry and replication. Viruses 2011, 3:293-311.

68. Du Z, Lang SM, Sasseville VG, Lackner AA, Ilyinskii PO, Daniel MD, Jung JU, Desrosiers RC: Identification of a nef allele that causes lymphocyte activation and acute disease in macaque monkeys. Cell 1995, 82:665-674.

69. Luo W, Peterlin BM: Activation of the T-cell receptor signaling pathway by Nef from an aggressive strain of simian immunodeficiency virus. J Virol 1997, 71:9531-9537.

70. Tschulena U, Sanzenbacher R, Muhlebach MD, Berger A, Munch J, Schindler M, Kirchhoff F, Plesker R, Coulibaly C, Panitz S, et al: Mutation of a diacidic motif in SIV-PBj Nef impairs T-cell activation and enteropathic disease. Retrovirology 2011, 8:14.

71. Baur AS, Sawai ET, Dazin P, Fantl WJ, Cheng-Mayer C, Peterlin BM: HIV-1 Nef leads to inhibition or activation of T cells depending on its intracellular localization. Immunity 1994, 1:373-384.

72. Collette $Y$, Dutartre H, Benziane A, Olive D: The role of HIV1 Nef in T-cell activation: Nef impairs induction of Th1 cytokines and interacts with the Src family tyrosine kinase Lck. Res Virol 1997, 148:52-58.

73. Luria S, Chambers I, Berg P: Expression of the type 1 human immunodeficiency virus Nef protein in T cells prevents antigen receptor-mediated induction of interleukin 2 mRNA. Proc Natl Acad SCi USA 1991, 88:5326-5330

74. Niederman TM, Garcia JV, Hastings WR, Luria S, Ratner L: Human immunodeficiency virus type 1 Nef protein inhibits NF-kappa B induction in human T cells. J Virol 1992, 66:6213-6219.

75. Tuosto L, Marinari B, Andreotti M, Federico M, Piccolella E: Vav exchange factor counteracts the HIV-1 Nef-mediated decrease of plasma membrane GM1 and NF-AT activity in T cells. Eur J Immunol 2003, 33:2186-2196

76. Fenard D, Yonemoto W, de Noronha C, Cavrois M, Williams SA, Greene WC Nef is physically recruited into the immunological synapse and potentiates T cell activation early after TCR engagement. J Immunol 2005, 175:6050-6057.

77. Fortin JF, Barat C, Beausejour Y, Barbeau B, Tremblay MJ: Hyper-responsiveness to stimulation of human immunodeficiency virus-infected CD4+ T cells requires Nef and Tat virus gene products and results from higher NFAT, NF-kappaB, and AP-1 induction. J Biol Chem 2004, 279:39520-39531.

78. Greenway A, Azad A, Mills J, McPhee D: Human immunodeficiency virus type 1 Nef binds directly to Lck and mitogen-activated protein kinase, inhibiting kinase activity. J Virol 1996, 70:6701-6708.

79. Hodge S, Novembre FJ, Whetter L, Gelbard HA, Dewhurst S: Induction of fas ligand expression by an acutely lethal simian immunodeficiency virus, SIVsmmPBj14. Virology 1998, 252:354-363.

80. Keppler OT, Tibroni N, Venzke S, Rauch S, Fackler OT: Modulation of specific surface receptors and activation sensitization in primary resting CD4+ T lymphocytes by the Nef protein of HIV-1. J Leukoc Biol 2006, 79:616-627

81. Manninen A, Saksela K: HIV-1 Nef interacts with inositol trisphosphate receptor to activate calcium signaling in T cells. J Exp Med 2002, 195:1023-1032.

82. Manninen A, Renkema GH, Saksela K: Synergistic activation of NFAT by HIV-1 nef and the Ras/MAPK pathway. J Biol Chem 2000, 275:16513-16517.

83. Schindler M, Munch J, Kutsch O, Li H, Santiago ML, Bibollet-Ruche F, Muller-Trutwin MC, Novembre FJ, Peeters M, Courgnaud V, et al: Nef-mediated suppression of T cell activation was lost in a lentiviral lineage that gave rise to HIV-1. Cell 2006, 125:1055-1067. 
84. Schrager JA, Der Minassian V, Marsh JW: HIV Nef increases T cell ERK MAP kinase activity. J Biol Chem 2002, 277:6137-6142.

85. Schrager JA, Marsh JW: HIV-1 Nef increases T cell activation in a stimulus-dependent manner. Proc Natl Acad Sci USA 1999, 96:8167-8172.

86. Simmons A, Aluvihare $V$, McMichael A: Nef triggers a transcriptional program in T cells imitating single-signal T cell activation and inducing HIV virulence mediators. Immunity 2001, 14:763-777.

87. Wang JK, Kiyokawa E, Verdin E, Trono D: The Nef protein of HIV-1 associates with rafts and primes $\mathrm{T}$ cells for activation. Proc Natl Acad SCi USA 2000, 97:394-399.

88. Neri F, Giolo G, Potesta M, Petrini S, Doria M: The HIV-1 Nef protein has a dual role in $\mathrm{T}$ cell receptor signaling in infected CD4+ T lymphocytes. Virology 2011, 410:316-326.

89. Haller C, Rauch S, Michel N, Hannemann S, Lehmann MJ, Keppler OT, Fackler OT: The HIV-1 pathogenicity factor Nef interferes with maturation of stimulatory T-lymphocyte contacts by modulation of N-Wasp activity J Biol Chem 2006, 281:19618-19630.

90. Rudolph JM, Eickel N, Haller C, Schindler M, Fackler OT: Inhibition of T-cell receptor-induced actin remodeling and relocalization of Lck are evolutionarily conserved activities of lentiviral Nef proteins. J Virol 2009, 83:11528-11539.

91. Stolp B, Abraham L, Rudolph JM, Fackler OT: Lentiviral Nef proteins utilize PAK2-mediated deregulation of cofilin as a general strategy to interfere with actin remodeling. J Virol 2010, 84:3935-3948.

92. Arhel N, Lehmann M, Clauss K, Nienhaus GU, Piguet V, Kirchhoff F: The inability to disrupt the immunological synapse between infected human T cells and APCs distinguishes HIV-1 from most other primate lentiviruses. J Clin Invest 2009, 119:2965-2975.

93. lafrate AJ, Bronson S, Skowronski J: Separable functions of Nef disrupt two aspects of T cell receptor machinery: CD4 expression and CD3 signaling. EMBO J 1997, 16:673-684

94. Bell I, Ashman C, Maughan J, Hooker E, Cook F, Reinhart TA: Association of simian immunodeficiency virus Nef with the T-cell receptor (TCR) zeta chain leads to TCR down-modulation. J Gen Virol 1998, 79(Pt 11):2717-2727.

95. Swigut T, Greenberg M, Skowronski J: Cooperative interactions of simian immunodeficiency virus Nef, AP-2, and CD3-zeta mediate the selective induction of T-cell receptor-CD3 endocytosis. J Virol 2003, 77:8116-8126.

96. Arhel NJ, Kirchhoff F: Implications of Nef: host cell interactions in viral persistence and progression to AIDS. Curr Top Microbiol Immunol 2009, 339:147-175.

97. Foster JL, Denial SJ, Temple BR, Garcia JV: Mechanisms of HIV-1 Nef function and intracellular signaling. J Neuroimmune Pharmacol 2011, 6:230-246.

98. Thoulouze MI, Sol-Foulon N, Blanchet F, Dautry-Varsat A, Schwartz O, Alcover A: Human immunodeficiency virus type-1 infection impairs the formation of the immunological synapse. Immunity 2006, 24:547-561

99. Haller C, Rauch S, Fackler OT: HIV-1 Nef employs two distinct mechanisms to modulate Lck subcellular localization and TCR induced actin remodeling. PLoS One 2007, 2:e1212.

100. Pan X, Rudolph JM, Abraham L, Habermann A, Haller C, Krijnse-Locker J, Fackler OT: HIV-1 Nef compensates for disorganization of the immunological synapse by inducing trans-Golgi network-associated Lck signaling. Blood 2012, 119:786-797.

101. Baur AS, Sass G, Laffert B, Willbold D, Cheng-Mayer C, Peterlin BM: The $\mathrm{N}$-terminus of Nef from HIV-1/SIV associates with a protein complex containing Lck and a serine kinase. Immunity 1997, 6:283-291.

102. Wolf D, Giese SI, Witte V, Krautkramer E, Trapp S, Sass G, Haller C, Blume K, Fackler OT, Baur AS: Novel (n)PKC kinases phosphorylate Nef for increased HIV transcription, replication and perinuclear targeting. Virology 2008, 370:45-54

103. Witte V, Laffert B, Gintschel P, Krautkramer E, Blume K, Fackler OT, Baur AS: Induction of HIV transcription by Nef involves Lck activation and protein kinase $C$ theta raft recruitment leading to activation of ERK $1 / 2$ but not NF kappa B. J Immunol 2008, 181:8425-8432.

104. Iwashima M, Irving BA, van Oers NS, Chan AC, Weiss A: Sequential interactions of the TCR with two distinct cytoplasmic tyrosine kinases. Science 1994, 263:1136-1139.

105. Lovatt M, Filby A, Parravicini V, Werlen G, Palmer E, Zamoyska R: Lck regulates the threshold of activation in primary $T$ cells, while both Lck and Fyn contribute to the magnitude of the extracellular signal-related kinase response. Mol Cell Biol 2006, 26:8655-8665.

106. Salmond RJ, Filby A, Qureshi I, Caserta S, Zamoyska R: T-cell receptor proximal signaling via the Src-family kinases, Lck and Fyn, influences T-cell activation, differentiation, and tolerance. Immunol Rev 2009, 228:9-22.

107. Palacios EH, Weiss A: Function of the Src-family kinases, Lck and Fyn in T-cell development and activation. Oncogene 2004, 23:7990-8000.

108. Zamoyska R, Basson A, Filby A, Legname G, Lovatt M, Seddon B: The influence of the src-family kinases, Lck and Fyn, on T cell differentiation, survival and activation. Immunol Rev 2003, 191:107-118.

109. Stolp B, Reichman-Fried M, Abraham L, Pan X, Giese SI, Hannemann S, Goulimari P, Raz E, Grosse R, Fackler OT: HIV-1 Nef interferes with host cell motility by deregulation of Cofilin. Cell Host Microbe 2009, 6:174-186.

110. Abraham L, Bankhead P, Pan X, Engel U, Fackler OT: HIV-1 Nef Limits Communication between Linker of Activated T Cells and SLP-76 To Reduce Formation of SLP-76-Signaling Microclusters following TCR Stimulation. J Immunol 2012, 189:1898-1910.

111. Gorska MM, Liang Q, Karim Z, Alam R: Uncoordinated 119 protein controls trafficking of Lck via the Rab11 endosome and is critical for immunological synapse formation. J Immunol 2009, 183:1675-1684.

112. Miller MD, Warmerdam MT, Gaston I, Greene WC, Feinberg MB: The human immunodeficiency virus-1 nef gene product: a positive factor for viral infection and replication in primary lymphocytes and macrophages. J Exp Med 1994, 179:101-113.

113. Spina CA, Kwoh TJ, Chowers MY, Guatelli JC, Richman DD: The importance of nef in the induction of human immunodeficiency virus type 1 replication from primary quiescent CD4 lymphocytes. J Exp Med 1994, 179:115-123.

114. Williams SA, Greene WC: Regulation of HIV-1 latency by T-cell activation. Cytokine 2007, 39:63-74.

115. Muratori C, Cavallin LE, Kratzel K, Tinari A, De Milito A, Fais S, D'Aloja P, Federico M, Vullo $V$, Fomina $A$, et al: Massive secretion by $T$ cells is caused by HIV Nef in infected cells and by Nef transfer to bystander cells. Cell Host Microbe 2009, 6:218-230.

116. Lenassi M, Cagney G, Liao M, Vaupotic T, Bartholomeeusen K, Cheng Y, Krogan NJ, Plemenitas A, Peterlin BM: HIV Nef is secreted in exosomes and triggers apoptosis in bystander CD4+ T cells. Traffic 2010, 11:110-122.

117. Witte V, Laffert B, Rosorius O, Lischka P, Blume K, Galler G, Stilper A, Willbold D, D'Aloja P, Sixt M, et al: HIV-1 Nef mimics an integrin receptor signal that recruits the polycomb group protein Eed to the plasma membrane. Mol Cell 2004, 13:179-190.

118. Glushakova S, Grivel JC, Suryanarayana K, Meylan P, Lifson JD, Desrosiers R, Margolis $L$ : Nef enhances human immunodeficiency virus replication and responsiveness to interleukin-2 in human lymphoid tissue ex vivo. J Virol 1999, 73:3968-3974.

119. Glushakova S, Munch J, Carl S, Greenough TC, Sullivan JL, Margolis L, Kirchhoff F: CD4 down-modulation by human immunodeficiency virus type 1 Nef correlates with the efficiency of viral replication and with CD4(+) T-cell depletion in human lymphoid tissue ex vivo. J Virol 2001, 75:10113-10117.

120. Homann S, Tibroni N, Baumann I, Sertel S, Keppler OT, Fackler OT: Determinants in HIV-1 Nef for enhancement of virus replication and depletion of CD4+ T lymphocytes in human lymphoid tissue ex vivo. Retrovirology 2009, 6:6.

121. Zou W, Denton PW, Watkins RL, Krisko JF, Nochi T, Foster JL, Garcia JV: Nef functions in BLT mice to enhance HIV-1 replication and deplete CD4 +CD8+ thymocytes. Retrovirology 2012, 9:44

122. Purbhoo MA, Liu H, Oddos S, Owen DM, Neil MA, Pageon SV, French PM, Rudd CE, Davis DM: Dynamics of subsynaptic vesicles and surface microclusters at the immunological synapse. Sci Signal 2010, 3:ra36.

123. Williamson DJ, Owen DM, Rossy J, Magenau A, Wehrmann M, Gooding Jل Gaus K: Pre-existing clusters of the adaptor Lat do not participate in early T cell signaling events. Nat Immunol 2011, 12:655-662.

124. Fukumoto R, Dundr M, Nicot C, Adams A, Valeri WW, Samelson LE, Franchini G: Inhibition of T-cell receptor signal transduction and viral expression by the linker for activation of T cells-interacting p12(I) protein of human T-cell leukemia/lymphoma virus type 1. J Virol 2007 , 81:9088-9099. 
125. Gerke C, Falkow S, Chien YH: The adaptor molecules LAT and SLP-76 are specifically targeted by Yersinia to inhibit T cell activation. J Exp Med 2005, 201:361-371.

126. Lee SH, Chung YH, Cho NH, Gwack Y, Feng P, Jung JU: Modulation of T-cell receptor signal transduction by herpesvirus signaling adaptor protein. Mol Cell Biol 2004, 24:5369-5382.

doi:10.1186/1478-811X-10-39

Cite this article as: Abraham and Fackler: HIV-1 Nef: a multifaceted modulator of T cell receptor signaling. Cell Communication and Signaling 2012 10:39.

\section{Submit your next manuscript to BioMed Central and take full advantage of:}

- Convenient online submission

- Thorough peer review

- No space constraints or color figure charges

- Immediate publication on acceptance

- Inclusion in PubMed, CAS, Scopus and Google Scholar

- Research which is freely available for redistribution 